\title{
TO EVALUATE THE ACCURACY OF ALVARADO SCORE IN THE DIAGNOSIS OF ACUTE APPENDICITIS-A PROSPECTIVE STUDY
}

Surendra Kumar Jain 1 , Saurabh Kothari², Vandana Jain ${ }^{3}$, Mayank Srivastava ${ }^{4}$

${ }^{1}$ Associate Professor, Department of General Surgery, JNUIMSRC, Jaipur.

${ }^{2}$ Assistant Professor, Department of General Surgery, S.N. Medical College, Jodhpur.

${ }^{3}$ Consultant Gynaecologist, D.C. Hospital, Jaipur.

${ }^{4}$ Assistant Professor, Department of Medicine, S.M.S. Medical College, Jaipur.

ABSTRACT
OBJECTIVES
The aim of our study is to correlate the diagnosis of acute appendicitis based on the Alvarado scoring system with histological
findings of the operated specimen and to analyse the incidence of negative appendectomy using this scoring system.

\section{METHODS}

A prospective study on 100 patients with clinical suspicion of acute appendicitis at MGIMS, Jaipur, from July 2011 to Dec 2012 was carried out. All patients were divided into three groups on the basis of Alvarado scoring system. USG, TLC and urinalysis was carried out in all patients. The decision of admission and surgery was made independent of the score. All removed appendix specimen were sent for histopathological examination.

\section{RESULTS}

Patients were in the range of 10-59 years with a mean age of 26.27. The male:female ratio in our study was 2.3:1. Abdominal pain was localized to RLQ in 89 patients, migration of pain from the umbilical region to right lower quadrant was present in $60 \%$. Right lower quadrant tenderness was seen in $95 \%$ cases. Rebound tenderness was present in $68 \%$ cases. Seventy five (75\%) cases were in the last score range of 7-10, suggestive of acute appendicitis with $54(72 \%)$ males and $21(28 \%)$ females. A statistically significant association between Alvarado score and histopathological diagnosis was found. The sensitivity, specificity and positive predictive value, negative predictive values of the scoring system were $80 \%, 70 \%, 96 \%$ and $28 \%$ respectively. The diagnostic accuracy of the scoring system was $79 \%$.

\section{CONCLUSION}

Though Alvarado score is easy, cheap and useful tool in preoperative evaluation of suspected cases of acute appendicitis, the final decision to operate cannot be based on Alvarado score only, particularly in the score below 7, as the diagnostic accuracy in our study was $79 \%$ only. Additional investigations like ultrasonography and computerized tomography required to arrive at a final diagnosis, especially in elderly patients, female patients and patients with equivocal score and low scores.

\section{KEYWORDS}

Alvarado Score, Acute Appendicitis.

HOW TO CITE THIS ARTICLE: Surendra Kumar Jain, Saurabh Kothari, Vandana Jain, Mayank Srivastava. "To Evaluate the Accuracy of Alvarado Score in the Diagnosis of Acute Appendicitis - A Prospective Study." Journal of Evolution of Medical and Dental Sciences 2015; Vol. 4, Issue 102, December 21; Page: 16739-16742, DOI: 10.14260/jemds/2015/2506

\section{INTRODUCTION}

The diagnostic accuracy of acute appendicitis remains unsatisfactory ranging from $25 \%$ to $90 \%$, being worse in females. Negative appendectomy rates of $20 \%$ to $40 \%$ has been documented and many surgeons accept the rate of $30 \%$ as inevitable. ${ }^{1}$ removing a normal appendix poses an economic burden to both the patient and the health resource. However, misdiagnosis can lead to perforation, abscess, lump formation, obstruction and peritonitis, thereby increasing the risk of morbidity and mortality particularly in the elderly where symptoms may be mild despite presence of a severely inflamed appendix.

Financial or Other, Competing Interest: None

Submission 09-12-2015, Peer Review 14-12-2015,

Acceptance 16-12-2015, Published 19-12-2015.

Corresponding Author:

S. K. Jain,

68, Vishveshwaraiah Nagar,

Triveni Nagar Mod,

Gopalpura Bypass,

Jaipur-302018, Rajasthan.

E-mail: skjain4dch@yahoo.co.in

DOI:10.14260/jemds/2015/2506
Difficulties in diagnosis often arise in very young, elderly and female patients of reproductive age because they usually have an atypical presentation and literature shows that $2 \%$ $7 \%$ of all adults on exploration have diseases other than appendicitis. $^{2}$ despite advances in diagnostic modalities diagnosis of acute appendicitis still remains challenged. Alvarado. $^{3} 1986$ proposed a scoring system based on 3 symptoms, 3 signs and 2 lab findings criteria for acute

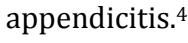




\begin{tabular}{|c|c|}
\hline \multicolumn{2}{|c|}{ Alvarado Score for Diagnosis of Acute Appendicitis } \\
\hline Criteria & Score \\
\hline \multicolumn{2}{|c|}{ Symptoms } \\
\hline Migratory RIF pain & 1 \\
\hline Anorexia & 1 \\
\hline Nausea and vomiting & 1 \\
\hline \multicolumn{2}{|c|}{ Signs } \\
\hline Tenderness in right iliac fossa & 2 \\
\hline Elevated temperature (Pyrexia $\geq$ & 1 \\
\hline 37.5 ${ }^{\circ}$ ) & 1 \\
\hline \multicolumn{2}{|c|}{ Laboratory } \\
\hline Leucocyte count $>10 \times 10^{9} / \mathrm{L}$ & 2 \\
\hline Shift to left (Neutrophilia) & 1 \\
\hline Total & $\mathbf{1 0}$ \\
\hline \multicolumn{2}{|c|}{ Table 1 } \\
\hline
\end{tabular}

\section{AIM}

The aim of our study is to correlate the diagnosis of acute appendicitis based on the Alvarado scoring system with histological findings of the operated specimen and to analyse the incidence of negative appendectomy using this scoring system.

\section{METHODS}

A prospective study on 100 patients who visited the surgical OPD at MGIMS, Jaipur, from July 2011 to Dec 2012 with clinical suspicion of acute appendicitis based on history and clinical examination were included in the study. Both males and females were included in the study. Patients with appendicular lump, generalized peritonitis, pregnancy, interval appendectomy were excluded from our study. A detailed history of site of pain, migration of pain, aggravating and relieving factors, fever, anorexia and vomiting was taken. All patients underwent physical examination for right iliac fossa tenderness, rebound tenderness and guarding. USG, TLC, DLC, and urine routine was done in all patients. The patients were scored on the basis of the Alvarado scoring system, but the decision of admission and surgery was made independent of the score. All removed appendix specimen were sent for histpathological examination.

\section{RESULTS}

\begin{tabular}{|c|c|c|}
\hline Age (Years) & $\begin{array}{c}\text { No. of Patients } \\
(\mathbf{n = 1 0 0 )}\end{array}$ & $\begin{array}{c}\text { Percentage } \\
(\mathbf{\%})\end{array}$ \\
\hline $10-20$ & 35 & 35 \\
\hline $21-30$ & 39 & 39 \\
\hline $31-40$ & 17 & 17 \\
\hline $41-50$ & 5 & 5 \\
\hline $51-60$ & 4 & 4 \\
\hline \multicolumn{2}{|c|}{ Table 2: Age Distribution of the Patients } \\
\hline
\end{tabular}

\begin{tabular}{|c|c|c|c|c|c|c|}
\hline \multicolumn{7}{|c|}{ Age in Years } \\
\hline & $\begin{array}{c}\mathbf{1 0 -} \\
\mathbf{2 0}\end{array}$ & $\mathbf{2 1 -}$ & $\mathbf{3 1}-$ & $\mathbf{4 1 -}$ & $\mathbf{5 1 -}$ & Total \\
\hline Male & 26 & 26 & 12 & 4 & 2 & $\mathbf{7 0}$ \\
\hline Female & 9 & 13 & 5 & 1 & 2 & $\mathbf{3 0}$ \\
\hline Total & $\mathbf{3 5}$ & $\mathbf{3 9}$ & $\mathbf{1 7}$ & $\mathbf{5}$ & $\mathbf{4}$ & $\mathbf{1 0 0}$ \\
\hline \multicolumn{7}{|c|}{ Table 3: Sex Distribution as Per } \\
Age Group of Patients
\end{tabular}

\begin{tabular}{|c|c|c|c|}
\hline \multicolumn{2}{|c|}{ Complaint } & $\begin{array}{l}\text { No. of Patients } \\
\quad(n=100)\end{array}$ & $\begin{array}{c}\text { Percentage } \\
(\%)\end{array}$ \\
\hline \multicolumn{2}{|c|}{ Pain abdomen RLQ } & 89 & 89 \\
\hline \multicolumn{2}{|c|}{ Migration of pain } & 60 & 60 \\
\hline \multicolumn{2}{|c|}{ Nausea/vomiting } & 95 & 95 \\
\hline \multicolumn{2}{|c|}{ Anorexia } & 83 & 83 \\
\hline \multicolumn{2}{|c|}{ Fever } & 32 & 32 \\
\hline \multirow{3}{*}{ Others } & Dysuria & 1 & \multirow{3}{*}{5} \\
\hline & Diarrhoea & 3 & \\
\hline & Constipation & 1 & \\
\hline \multicolumn{4}{|c|}{ Table 4: Symptoms } \\
\hline
\end{tabular}

Abdominal pain was localized to RLQ in 89 patients and around the umbilicus in the remaining 11. Migration of pain from the umbilical region to right lower quadrant was present in $60 \%$ cases. Nausea or vomiting was a predominant symptom present in $95 \%$ cases. Anorexia was experienced by $83 \%$ patients. Fever was present in only $32 \%$ of patients. Murphy's triad of symptoms, i.e. pain abdomen, vomiting and fever was seen in $29 \%$ of the cases (Table 4 ).

\begin{tabular}{|c|c|c|}
\hline Signs & $\begin{array}{c}\text { No. of Patients } \\
(\mathbf{n = 1 0 0 )}\end{array}$ & $\begin{array}{c}\text { Percentage } \\
\text { (\%) }\end{array}$ \\
\hline RLQ Tenderness & 95 & 95 \\
\hline Rebound tenderness & 68 & 68 \\
\hline Guarding & 34 & 34 \\
\hline Tachycardia & 73 & 73 \\
\hline Temperature $>99^{\circ} \mathrm{F}$ & 32 & 32 \\
\hline \multicolumn{2}{|r|}{ Table 5: Clinical Signs } \\
\hline
\end{tabular}

Table 5: Clinical Signs

Table 5 shows the clinical signs noted in the patients. Right lower quadrant tenderness was seen in 95\% cases. Rebound tenderness was present in $68 \%$ cases. Guarding was present in only $34 \%$ of cases and it reflects the severity of inflammation; $73 \%$ cases had tachycardia; $32 \%$ cases were febrile with temperature above $37.5^{\circ} \mathrm{C}$.

\begin{tabular}{|l|c|c|}
\hline \multicolumn{1}{|c|}{ Diagnosis } & $\begin{array}{c}\text { No. of } \\
\text { Patients }\end{array}$ & $\begin{array}{c}\text { Percentage } \\
\%\end{array}$ \\
\hline Acute appendicitis & & \\
Gangrenous appendix & 75 & \\
Sub-Acute appendicitis & 6 & \\
Acute catarrhal appendix & 4 & \\
Acute haemorrhagic & 2 & \\
appendicitis & 1 & 90 \\
Acute haemorrhagic necrotic & 1 & \\
appendicitis & 1 & \\
Acute appendicitis with & & \\
carcinoid tumor & 1 & \\
Normal appendix & 1 & \\
Meckel's diverticulitis & 2 & 10 \\
Non-specific mesenteric & 6 & \\
adenitis & & \\
Salpingitis Negative exploration & T0TAL & \\
\hline \multicolumn{2}{|c|}{ Table 6: HPE and Operative Findings } \\
\hline \multicolumn{2}{|c|}{} \\
\hline
\end{tabular}

\begin{tabular}{|c|c|c|c|c|}
\hline \multirow{2}{*}{ Appendicectomy } & \multicolumn{2}{|c|}{$\begin{array}{c}\text { Appendicitis on } \\
\text { H/P } \\
\text { Examination }\end{array}$} & \multicolumn{2}{c|}{$\begin{array}{c}\text { Negative } \\
\text { Appendicectomy } \\
\text { Rate }\end{array}$} \\
\cline { 2 - 6 } & No. & $\begin{array}{c}\text { Percentage } \\
(\%)\end{array}$ & No. & $\begin{array}{c}\text { Percentage } \\
\text { (\%) }\end{array}$ \\
\hline Male (70) & 66 & 94 & 4 & 5.71 \\
\hline Female (30) & 24 & 80 & 6 & 20 \\
\hline Total (100) & $\mathbf{9 0}$ & $\mathbf{9 0}$ & $\mathbf{1 0}$ & $\mathbf{1 0}$ \\
\hline \multicolumn{4}{|r|}{ Table 7: Negative Appendicectomy Rate } \\
\hline
\end{tabular}


Table 6 show the diagnoses after surgery conducted on 100 patients of suspected acute appendicitis. Appendicitis was confirmed in 90 patients by histopathological examination. Gangrenous appendices were present in 6 patients. The negative appendectomy rate was $10 \%$. (Table 7 ).

\begin{tabular}{|c|c|c|c|c|c|}
\hline \multirow{2}{*}{ Score } & $\begin{array}{c}\text { No. of } \\
\text { Patients } \\
(\mathbf{n = 1 0 0 )}\end{array}$ & No. & $\begin{array}{c}\text { Percentage } \\
\text { (\%) }\end{array}$ & No. & $\begin{array}{c}\text { Percentage } \\
\text { (\%) }\end{array}$ \\
\cline { 3 - 6 } & 6 & 3 & 50 & 3 & 50 \\
\hline $1-4$ & 19 & 13 & 68.4 & 6 & 31.6 \\
\hline $5-6$ & 75 & 54 & 72 & 21 & 28 \\
\hline $7-10$ & 100 & $\mathbf{7 0}$ & & $\mathbf{3 0}$ & \\
\hline Total & Table 8: Showing Distribution of Patients \\
\hline \multicolumn{6}{|c|}{} \\
\hline
\end{tabular}

The frequency of the patients according to Alvarado scoring system is given in Table 8. None of the patients had an Alvarado score below 4. Mean score was $7.4 \pm 1.55$. Group wise results were as follows: In the first group, $6(6 \%)$ patients had Alvarado score 1-4, which was not suggestive of acute appendicitis. In this group there were two negative appendectomies and no other pathology was found in both these cases. But the other four cases showed acute and subacute appendicitis. Nineteen (19\%) cases were categorized as within 5-6 (Equivocal score) with a sex distribution of $13(68.4 \%)$ males and $6(31.6 \%)$ females. In this group there were six negative appendectomies; one case was that of salpingitis, one of mesenteric lymphadenitis and no pathology was found in the remaining four cases.

Seventy five $(75 \%)$ cases were in the last score range of 7 10 , suggestive of acute appendicitis with $54(72 \%)$ males and 21(28\%) females. There were two negative appendectomies in this group, out of which one case was of Meckel's diverticulitis and one of salpingitis. All the patients with gangrenous appendicitis $(n=6)$ and perforated appendicitis $(n=6)$ in the series were within the score range of 7-10.

\begin{tabular}{|c|c|c|c|c|}
\hline \multirow{2}{*}{$\begin{array}{c}\text { Diagnostic Test } \\
\text { Result }\end{array}$} & \multicolumn{3}{|c|}{$\begin{array}{c}\text { Histopathological } \\
\text { Diagnosis }\end{array}$} & \multirow{5}{*}{$\begin{array}{c}\mathrm{p} \\
\text { value } \\
0.0021\end{array}$} \\
\hline & Appendicitis & Normal & Total & \\
\hline Score $\geq 7$ positive & 73 & 2 & 75 & \\
\hline Score $<7$ negative & 17 & 8 & 25 & \\
\hline Total & 90 & 10 & 100 & \\
\hline $\begin{array}{l}\text { Tab } \\
\text { scor }\end{array}$ & $\begin{array}{l}\text { SSociation b } \\
\text { Histopatho }\end{array}$ & $\begin{array}{l}\operatorname{een} A \\
\text { Cal Di }\end{array}$ & & \\
\hline
\end{tabular}

The above table demonstrates a statistically significant association between Alvarado score and histopathological diagnosis. The sensitivity, specificity and positive predictive value, negative predictive values of the scoring system were $80 \%, 70 \%, 96 \%$ and $28 \%$ respectively. The overall diagnostic accuracy of the scoring system was $79 \%$.

\begin{tabular}{|c|c|c|c|}
\hline Gender & Below 7 & Acute Appendicitis & Normal Appendix \\
\hline Male & 16 & 13 & 3 \\
\hline Female & 09 & 04 & 5 \\
\hline Total & $\mathbf{2 5}$ & $\mathbf{1 7}$ & $\mathbf{8}$ \\
\hline \multicolumn{3}{|c|}{ Table 10: Diagnostic accuracy } \\
of Alvarado score below 7 \\
\hline
\end{tabular}

The diagnostic accuracy of the score below 7 was only $32 \%$

\begin{tabular}{|c|c|c|c|}
\hline Gender & Above 7 & Acute Appendicitis & Normal Appendix \\
\hline Male & 54 & 53 & 1 \\
\hline Female & 21 & 20 & 1 \\
\hline Total & $\mathbf{7 5}$ & $\mathbf{7 3}$ & $\mathbf{2}$ \\
\hline \multicolumn{3}{|c|}{ Table 11: Diagnostic accuracy } \\
of Alvarado score 7 and above
\end{tabular}

The diagnostic accuracy of the score above 7 was about $97 \%$.

\section{DISCUSSION}

Appendectomy is the most frequently performed surgery. Each year 2.5 lakh appendectomies are done in USA for with $15 \%$ negative appendectomy rate.

This negative rate has been accepted as an unavoidable consequence of the principal of early operation to prevent complications. Considerable effort has gone into strategies aimed at reducing the negative appendectomy rate. The demographic profile revealed a mean age of 26.27 in our study similar to that shown by Tauro LF et al. 2009 (26\%) and Gaitini D. 6 et al. in 2008 (28.4\%). Our study had male-to-female ratio of 2.3:1, which is comparable to studies by Nautiyal $\mathrm{H}$ et al. ${ }^{8.6}$ (2010) 1.89 and Soomro AG et al. ${ }^{7}$ (2008) 1.94:1, Talukder DB et al. ${ }^{8}$ found male-to-female ratio as 1.38:1 (Males-58\%, Females-42\%); 89\% presented with right lower quadrant pain and migration of pain was seen in $60 \%$ cases in our study.

These results compared well with MA Alavi's. ${ }^{9}$ study, where $83.37 \%$ had right lower quadrant pain and $48.78 \%$ had migration of pain. On statistical analysis of the collected data, there were 70 males and 30 females who underwent appendectomy; appendicitis was confirmed in 66 males and 24 females giving a negative appendectomy rate of $5.71 \%$ in males and $20 \%$ in females with an overall negative appendectomy rate of $10 \%$, which are comparable with that of Jawaid A et al. ${ }^{10}(7 \%)$, Alavi MA et al. ${ }^{9}(10.97 \%)$, Ikramullah Khan et al. (2005). ${ }^{11}$ conducted a study to evaluate Alvarado scoring system for the diagnosis of acute appendicitis in 100 patients at Khyber Teaching Hospital, Peshawar. Their negative appendectomy rate was $15.6 \%$ (Male $12 \%$, Female $17.9 \%)$. Literature shows that if the negative appendectomy rate is less than $10 \%-15 \%$, then the surgeon is operating on too few patients, thus increasing the risk of complications.

Various scoring systems are being used to aid the diagnosis of acute appendicitis and bring down the negative appendectomy rates of which the Alvarado scoring system is commonly used. The score $\geq 7$ indicates high probability of acute appendicitis. In the present study, the overall sensitivity and specificity of Alvarado score was $80 \%$ and $70 \%$ respectively. The PPV and NPV were $96 \%$ and $28 \%$ respectively. The diagnostic accuracy of the scoring system was $79 \%$. The original article by Alvarado. ${ }^{10}$ investigated 305 patients and reported sensitivity, specificity and PPV of the scoring system as $81 \%, 74 \%$ and $92 \%$ similar to our results, although the NPV of $46 \%$ was higher than our study. Our findings echoed those of various other authors as outlined in table12. However NPV was found to be much higher in most of the studies. 


\begin{tabular}{|c|c|c|c|c|c|c|}
\hline Author & Year & Sensitivity & Specificity & PPV & NPV & N \\
\hline A Alvarado. $^{10}$ & $(1986)$ & $81 \%$ & $74 \%$ & $92 \%$ & $46 \%$ & 305 \\
\hline Fenyo G et al..$^{12}$ & $(1997)$ & $73 \%$ & $87 \%$ & - & - & 475 \\
\hline Jawaid A et al. ${ }^{10}$ & $(1999)$ & $78 \%$ & $89 \%$ & $97 \%$ & - & 401 \\
\hline Schneider et al. & $(2007)$ & $72 \%$ & $81 \%$ & $65 \%$ & $85 \%$ & 588 \\
\hline Dey S et al. & $(2010)$ & $94.2 \%$ & $70 \%$ & $86 \%$ & $69.8 \%$ & 155 \\
\hline Present Study & $\mathbf{( 2 0 1 2 )}$ & $\mathbf{8 0 \%}$ & $\mathbf{7 0 \%}$ & $\mathbf{9 6 \%}$ & $\mathbf{2 8 \%}$ & $\mathbf{1 0 0}$ \\
\hline \multicolumn{7}{|l|}{ Table 12: Alvarado Score-Comparison with Other Studies } \\
\hline
\end{tabular}

The high PPV (96\%) and significant association (P = 0.0021 ) of Alvarado score in our study was due to a higher proportion of patients being males with a score of $>7$, which is highly indicative of acute appendicitis (Table 7 of observation) However, in our study patients with an equivocal score and low score included elderly patients and females who may have gynaecological conditions simulating appendicitis or vice versa, hence additional investigations (Like ultrasound or CT) is required to confirm the diagnosis.

\section{CONCLUSION}

Though Alvarado score is easy, cheap and useful tool in preoperative evolution of suspected cases of acute appendicitis; the final decision to operate cannot be based on Alvarado score only as the diagnostic accuracy in our study was 79\%. Additional investigations like ultrasonography and computed tomography required to arrive at a final diagnosis, especially in elderly patients, female patients and patients with equivocal and low Alvarado scores.

\section{REFERENCES}

1. Chang FC, Hogle HH, Welling DR. The Fate of Negative Appendix, Am J Surg 1973;126:752-754.

2. Gilmore OJA, Jones D, Ynag Q. Appendicitis and mimicking conditions. Lancet 1975; II: 421-4. Alvarado A; A Practical Score for Early Diagnosis of Acute Appendicitis. Ann Emerg Med 1986;15:557-564.

3. Sim KT, Picone S, Crde M, et al. Ultrsound with graded compression in the evaluation of acute appendicitis. J Natl Med Assoc 1989;81(9):954-957.

4. Tauro LF, Premanand TS, Aithala PS, George C, Suresh HB, Acharya D, et al. Ultrasonography is still a useful diagnostic tool in acute appendicitis. Journal of Clinical and Diagnostic Research. 2009 Oct;3:1731-1736.
5. Gaitini D, Beck-Razi N, Mor-Yosef D, Fischer D, Ben Itzhak O, Krausz MM, et al. Diagnosing acute appendicitis in adults: accuracy of color Doppler sonography and MDCT compared with surgery and clinical follow-up. AJR Am J Roentgenol. 2008 May;190(5):1300-6.

6. Soomro AG, Siddiqui FG, Abro AH, Abro S, Shaikh NA and Memon AS. Diagnostic Accuracy of Alvarado Scoring System in Acute Appendicitis. JLUMHS 2008.

7. Talukdar DB and Siddiq AKMZ. Modified Alvarado scoring system in the diagnosis of acute appendicitis. JAFMC Bangladesh 2009;5(1):18-20.

8. Alavi MA, Suleri M, Haq AU, et al. Practicality of modified score in diagnosis of acute appendicitis. Pak J of Surg 2007; $23: 4$

9. Jawaid A, Asad A, Motiei A, Munir A, Bhutto E, Choudry H, et al. Clinical scoring system: a valuable tool for decision making in cases of acute appendicitis. J Pak Med Assoc 1999 Oct; 49(10):254-9.

10. Ikramullah Khan, Ata Ur Rehman. Application of Alvarado system in diagnosis of acute appendicitis. J Ayub Med Coll Abbottabad 2005;17:3.

11. Fenyo G, Lindberg G, Blind P, et al. Diagnostic decision support in suspected acute appendicitis: validation of a simplified scoring system. Eur J Surg 1997 Nov;163(11):831-8.

12. Schneider C, Kharbanda A, Bachur R. Evaluating appendicitis in scoring systems using a prospective pediatric cohort. Ann of Emg Med 2007;49:6.

13. Dey S, Mohanta PK, Baruah AK, Kharga B, Bhutia KL, Singh VK. Alvarado scoring in acute appendicitis - A clinicopathological correlation. Indian J Surg 2010;72(4):290-293. 